Article

\title{
A Porous Tungsten Substrate for Catalytic Reduction of Hydrogen by Dealloying of a Tungsten-Rhenium Alloy in an Aqueous Solution of Hydrochloric Acid
}

\author{
Aleksander A. Chernyshev ${ }^{1,2, *}$ and Evgenia V. Nikitina ${ }^{1,2}$ (D) \\ 1 Department of Technology of Electrochemical Production, Institute of Chemical Technology, \\ Ural Federal University, 620002 Yekaterinburg, Russia; neekeetina@mail.ru \\ 2 The Institute of High Temperature Electrochemistry of the Ural Branch of the Russian Academy of Sciences, \\ 620137 Yekaterinburg, Russia \\ * Correspondence: aac-vp@ihte.uran.ru
}

check for updates

Citation: Chernyshev, A.A.; Nikitina, E.V. A Porous Tungsten Substrate for Catalytic Reduction of Hydrogen by Dealloying of a Tungsten-Rhenium Alloy in an Aqueous Solution of Hydrochloric Acid. Appl. Sci. 2022, 12, 1029. https://doi.org/ 10.3390/app12031029

Academic Editors: Suzdaltsev Andrey and Oksana Rakhmanova

Received: 29 October 2021 Accepted: 17 January 2022 Published: 19 January 2022

Publisher's Note: MDPI stays neutral with regard to jurisdictional claims in published maps and institutional affiliations.

Copyright: (c) 2022 by the authors. Licensee MDPI, Basel, Switzerland. This article is an open access article distributed under the terms and conditions of the Creative Commons Attribution (CC BY) license (https:/ / creativecommons.org/licenses/by/ $4.0 /)$.

\begin{abstract}
Selective dissolution of a tungsten (85 wt.\%)-rhenium (15 wt.\%) alloy with rhenium in hydrochloric acid at the temperature of $298 \mathrm{~K}$ and anodic polarization modes was carried out to develop a porous catalytic substrate and to recycle rare metals. The parameters of the effective selective anodic dissolution of the tungsten-rhenium alloy, including the differences in applied potentials and electrolyte composition, were found. It was established that samples of the tungstenrhenium alloy possess the smallest average pore size after being exposed for $6000 \mathrm{~s}$. The obtained porous tungsten samples were characterized by X-ray diffraction and scanning electron spectroscopy. A thermodynamic description of the processes occurring during the anodic selective dissolution of a binary alloy was proposed. In the course of the work, the selectivity coefficient was determined using an X-ray fluorescence wave-dispersion spectrometer XRF-1800. The existence of a bimodal structure on the tungsten surface after dealloying was proved.
\end{abstract}

Keywords: tungsten; rhenium; dealloying; anodic polarization; developed surface; catalyst for HER

\section{Introduction}

The search for renewable, environmentally friendly energy sources, which is triggered by the depletion of fossil energy and environmental pollution [1,2], has determined the important role of hydrogen energy [3]. Despite the high specific energy release (160 MJ/g), its significant disadvantage and limitation include the significant consumption of electricity required for hydrogen electrolysis [4]. The main task in the development of hydrogen energy is to reduce the overvoltage of the hydrogen evolution reaction (HER), which will reduce the total energy consumption. Therefore, new materials should be based on metals with high electrocatalytic activity of cathodic hydrogen release that will lead to a decrease in the overvoltage of HER and, consequently, to a reduction in the hydrogen production cost.

Recently, base metals such as $\mathrm{Ni}, \mathrm{Co}, \mathrm{W}$, or Mo [2,5-12]; their alloys [2,5-13]; and base metal-containing materials such as sulfides, nitrides, phosphides, and carbides of transition metals have been recognized as effective HER catalysts [14-19]. This is due to their chemical stability; their low cost; and, most importantly, to the low overvoltage of hydrogen release [20].

Tungsten, having unique properties such as a high melting point and chemical resistance, is a promising material for the HER from alkaline electrolytes [21,22]. The potential use of a porous layer of tungsten obtained in the process of dealloying accompanied with the removal of the second metal has determined the interest in the study of tungsten-rhenium alloys. Due to its thermodynamic properties, a tungsten-rhenium alloy is promising for the formation of a highly porous surface by anodic dissolution. The mechanism of anodic formation of such structures has received considerable scientific and technological interest. 
A large number of works are devoted to the synthesis and study of nanostructured mesoporous materials obtained by various methods at ordinary temperatures. The current state of the problem is analyzed elsewhere [23-25]. There are several common methods for synthesizing mesoporous materials. For example, one of them is based on the use of nanotemplates such as silicon dioxide or organic polymers as structure-forming agents for metallic nanolayer formation. After chemical removal of the template, nanopores are formed. We would also like to mention here the method of thermal decomposition of unstable nitrogenous metal compounds, which are used to form nanofoams with a record low density. The removal of a more electronegative alloy component (so-called dealloying) is less widespread and is mainly used to obtain precious metals in the mesoporous stategold, silver, and platinoids [26,27]. Thus, Hakamada and Mabuchi [28] presented a method for the preparation of mesoporous palladium in an aqueous sulfuric acid solution.

The existing works on the electrochemical behavior of anodes made of binary alloys in low-temperature electrolytes are scattered and, as a rule, do not pay much attention to the formed near-surface structures and the development of the electrode surface. The situation is somewhat better in low-temperature electrolytes [29].

Currently, the research in the field of mesoporous materials is shifting its focus toward the materials' synthesis. Apart from impressive specific surface areas, these materials demonstrate a sufficiently high electronic conductivity and high reaction capacity. The possibility of extracting expensive rhenium and simultaneous formation of a porous tungsten structure, which can be used as a substrate for catalyst deposition, from a tungsten-rhenium alloy is of considerable interest. The main task of this work is to evaluate the change in the structure of the tungsten-rhenium alloy depending on the electrolysis conditions and the composition of the solution at constant temperature.

Modern electrochemical materials science, using advancements in the field of nanomaterials, opens up new opportunities in the development of electric and hybrid vehicles, power supplies, and portable electronics. Various mesoporous materials are being intensively studied as electrodes for supercapacitors, biosensors, and catalysts.

Within the framework of this research, the main attention is focused on the structure of a metallic material synthesized by the selective dissolution of a tungsten and rhenium alloy. In further studies, it is planned to establish the patterns that govern the formation, structure, and properties of the tungsten structures.

The purpose of this work is to study the regularities of the formation of a porous structure on the surface of tungsten during selective anodic dissolution of a tungsten (85 wt. \%)-rhenium (15 wt. \%) alloy in a solution of hydrochloric acid at $298 \mathrm{~K}$; to develop the technology for obtaining nanostructured electrode materials with a developed surface; and to study their physicochemical properties. There is a lack of scientific literature on the tungsten-containing systems of this type. There are only works on electrochemical dealloying of other materials in aqueous solutions. Tungsten is a promising catalyst and/or substrate. Production of nanoporous tungsten is also of great practical interest. Processing of tungsten-rhenium alloys is important to prove the possibility of extracting more expensive rhenium [30-32]. The method of selective dissolution, in addition to the synthesis of a bimodal structure at the surface of tungsten, provides the extraction of rhenium in the form of chlorrenic acid or potassium chlorrenate.

\section{Materials and Methods}

Electrochemical measurements were carried out using an Autolab PGStat 302N electrochemical workstation (Metrohm, Switzerland).

Experimental measurements were carried out in a standard three-electrode twochamber glass cell using the following working electrodes: high-purity rhenium with a surface area of $1.06 \mathrm{~cm}^{2}$, high-purity tungsten $\left(0.72 \mathrm{~cm}^{2}\right)$, and a tungsten-rhenium alloy BP-20 (Russia) containing $15 \mathrm{wt}$. \% rhenium with a surface of $2.5 \mathrm{~cm}^{2}$. A rod made of spectrally pure graphite was used as a counter electrode, and a silver chloride electrode (SCE) was used as the reference electrode. All potentials in this work are given with 
respect to SCE. A Luggin capillary was used to eliminate the ohmic drop through the electrolyte solution.

The surfaces of the working electrodes were prepared by cleaning $\mathrm{SiC}$ paper with different grain sizes, followed by polishing with diamond powder. Linear voltammetry data were obtained for all electrodes from hydrochloric acid solutions; their compositions are shown in Table 1.

Table 1. Compositions of solutions for electrochemical studies.

\begin{tabular}{ccccc}
\hline Component & Solution $\mathbf{1}$ & Solution $\mathbf{2}$ & Solution $\mathbf{3}$ & Solution $\mathbf{4}$ \\
\hline $\mathrm{HCl}, \mathrm{g} \mathrm{L}^{-1}$ & 200 & 200 & 350 & 350 \\
$\mathrm{KCl}, \mathrm{g} \mathrm{L}^{-1}$ & 0 & 340 & 0 & 340 \\
\hline
\end{tabular}

All solutions were prepared based on distilled water with the use of potassium chloride and hydrochloric acid of high purity. Electrochemical studies were carried out in the ambient air at an environment temperature of $298 \mathrm{~K}$ and a rate of potential change of $1 \mathrm{mV} / \mathrm{s}$.

Based on linear voltammetry, the potential of the rhenium separation from a tungstenrhenium alloy was determined. To confirm the selective separation of rhenium from the alloy, chronoamperometry was performed at a constant potential (Econst $=600 \mathrm{mV}(\mathrm{SCE})$ ) within 30,000 s.

The surface of porous tungsten samples obtained as a result of anodic potentiodynamic polarization (chronoamperometry) was analyzed by the micro-X-ray spectral method using the TESCAN MIRA 3 LMU auto-emission electron microscope (TESCAN, Czechia) and the $\mathrm{X}$-ray phase method using the Rigaku D/MAX-2200VL/PC automatic X-ray diffractometer (Rigaku, Japan).

\section{Results}

Linear voltammetry was used to study the anodic process occurring on individual rhenium, tungsten, and tungsten-rhenium electrodes. Figure 1 shows that rhenium was dissolved in all solutions according to the mechanism of the delayed ionization. The active dissolution stage began at the potential of $600 \mathrm{mV}$ relative to the silver chloride electrode. At current densities below $20 \mathrm{~A} / \mathrm{m}^{2}$, the addition of potassium chloride practically did not affect the course of the polarization curve. However, at high current densities above $2500 \mathrm{~A} / \mathrm{m}^{2}$, the addition of potassium chloride caused electrode salt passivation and the formation of potassium chlorrenate.

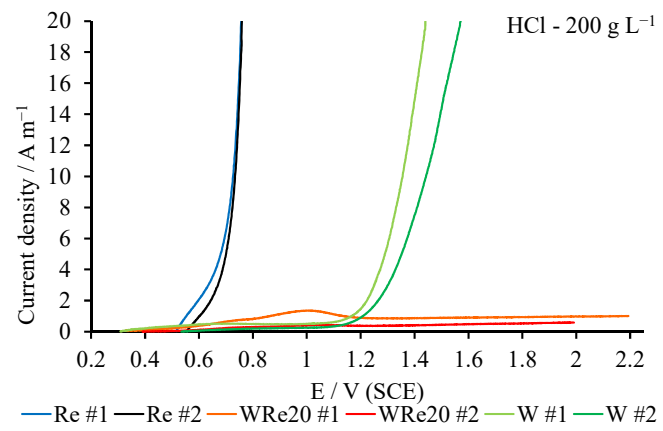

(a)

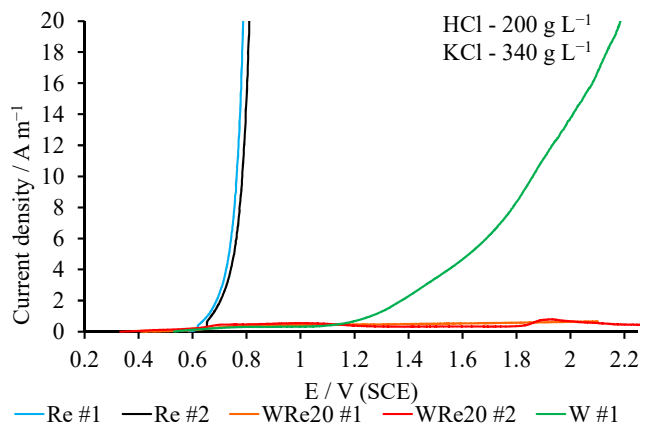

(b)

Figure 1. Cont. 


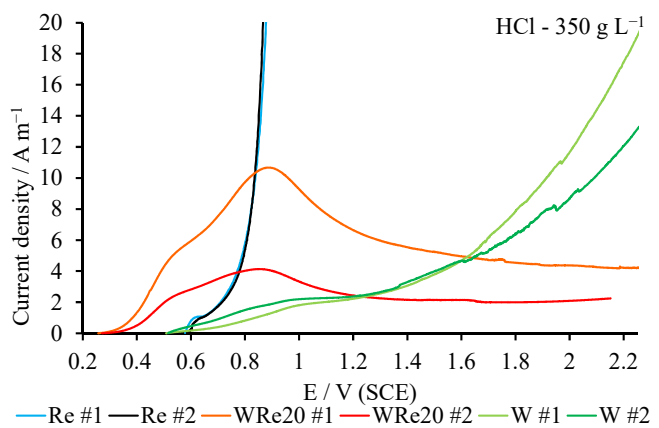

(c)

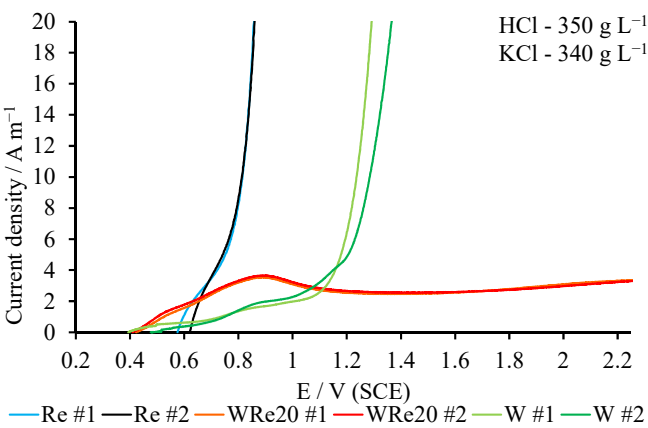

(d)

Figure 1. The data of linear voltammetry in different solutions: (a) Solution 1; (b) Solution 2; (c) Solution 3; (d) Solution 4.

The process taking place on the tungsten electrode was accompanied with significant polarization. The active stage began at the potential of $1100 \mathrm{mV}$ (SCE) and was accompanied by abundant gas release. At the same time, there was no decrease in the mass of the electrode itself. Therefore, tungsten dissolution and the active release of gaseous oxygen were not observed.

No pronounced processes were registered in solutions 1 and 2 for the tungstenrhenium alloy. Pronounced peaks associated with the selective dissolution of rhenium were observed in solutions 3 and 4 .

The potential of rhenium release in hydrochloric acid solutions was determined on the basis of the obtained voltage dependences. The active dissolution stage of rhenium began at a potential of $600 \mathrm{mV}$ (SCE) for both individual rhenium and the tungsten-rhenium alloy.

The extraction of rhenium from a tungsten-rhenium alloy depending on the processing time was carried out using chronoamperometry at a constant potential (Figure 2).

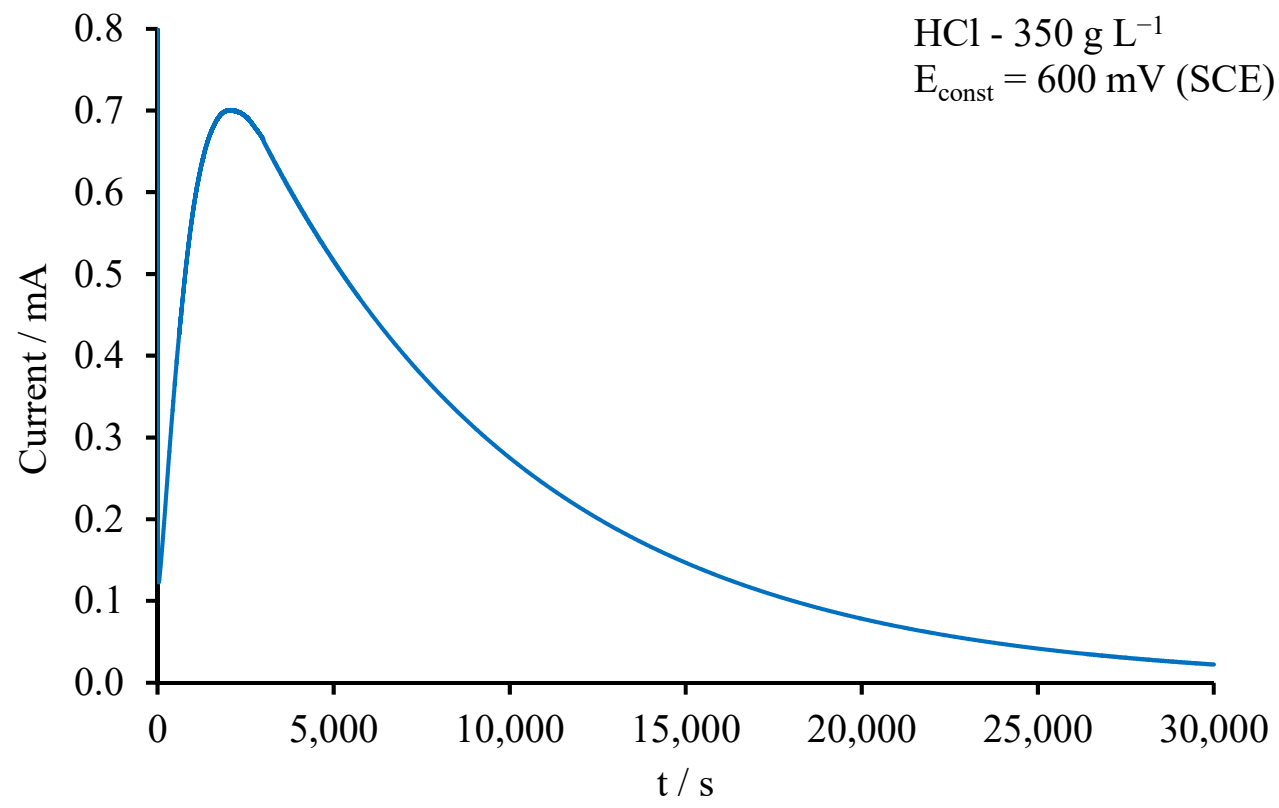

Figure 2. Chronoamperogram of tungsten-rhenium alloy dissolution.

The samples of the tungsten-rhenium alloy after potentiostatic dealloying were subjected to X-ray phase analysis using a Rigaku D/MAX-2200VL/PC X-ray diffractometer (Rigaku, Japan) (Figure 3). It was found that after dealloying, new phases (for example, an oxide film) were not formed on the surface of the samples. This indicates the absence of the process passivation and favorably affects the depth of extraction of rhenium from the alloy. 


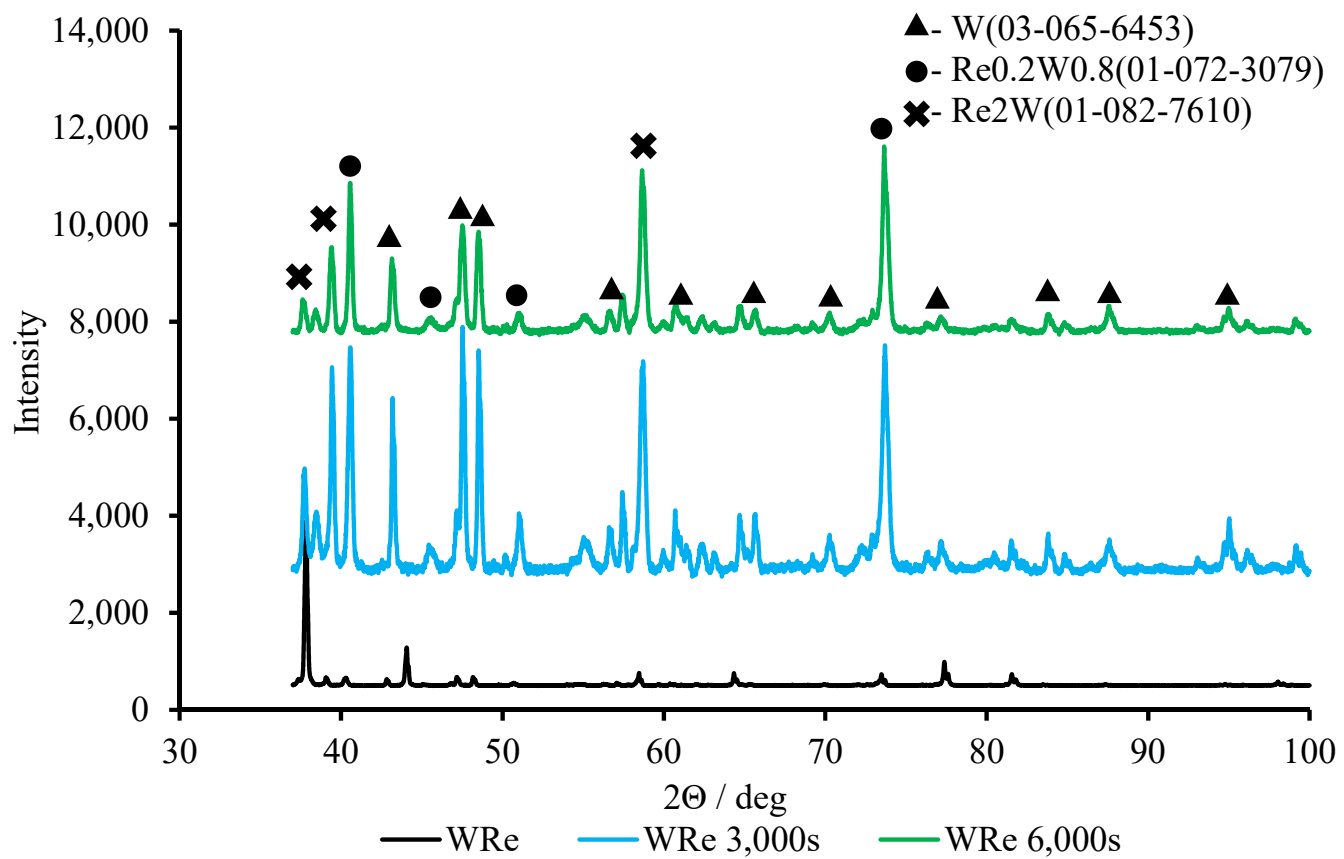

Figure 3. Diffractograms of initial alloy, alloy after $3000 \mathrm{~s}$ exposure in the solution, and alloy after $6000 \mathrm{~s}$ exposure in the solution.

To determine the change in the alloy composition, SEM studies of the samples' surfaces were carried out using energy-dispersive X-ray spectroscopy (EDS) with the TESCAN MIRA 3 LMU (Figure 4).
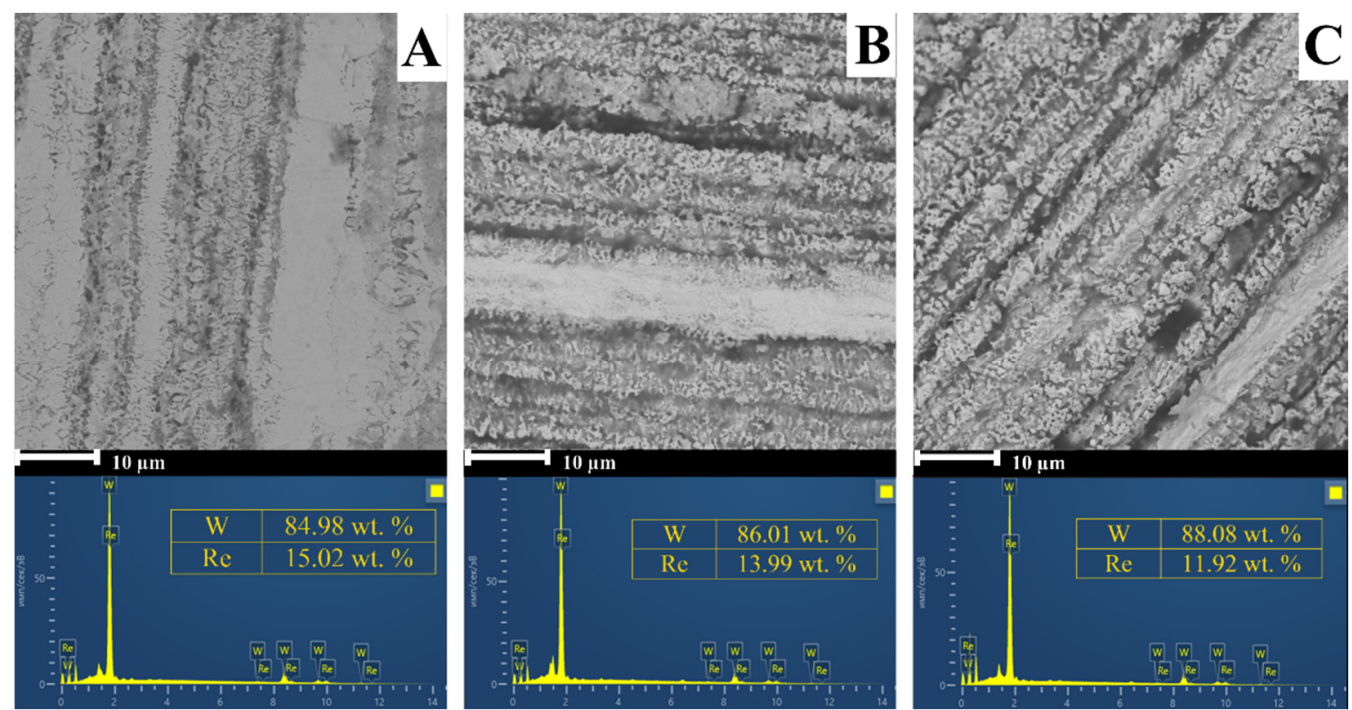

Figure 4. Microstructure of initial alloy (A), alloy after 3000 s exposure in solution (B), and alloy after $6000 \mathrm{~s}$ exposure in the solution $(\mathbf{C})$.

Figure 4 shows that with the increase in the duration of the electrolysis, the sample surface dissolved selectively, forming a rough surface. The EDS spectra confirmed by linear voltammetry demonstrate that at a given potential, selective dissolution of rhenium occurs. In the first $3000 \mathrm{~s}$, the process of active dissolution of rhenium proceeds and a strong change in the surface occurs. With the continuation of the electrolysis, the diffusion of rhenium ions from the electrode into the electrolyte bulk is hampered by the emerging bimodal structures, which leads to a slowdown but not to an interruption in the dealloying process. The EDS spectra of the sample after $6000 \mathrm{~s}$ exposure confirm this. To confirm the EDS data, 
the wavelengths of the samples were also analyzed using an XRF-1800 dispersive X-ray fluorescence spectrometer (Shimadzu, Japan). According to the results of the analysis, the concentration of rhenium in the alloy changed from $15 \mathrm{wt} . \%$ in the initial electrode up to $14 \mathrm{wt} . \%$ after $3000 \mathrm{~s}$, to $12 \mathrm{wt} . \%$ after $6000 \mathrm{~s}$, and to $6.8 \mathrm{wt} . \%$ after $30,000 \mathrm{~s}$.

The dealloying penetration depth was estimated by SEM images of the sample crosssection using EDS with the TESCAN MIRA 3 LMU (Figure 5 and Table 2).
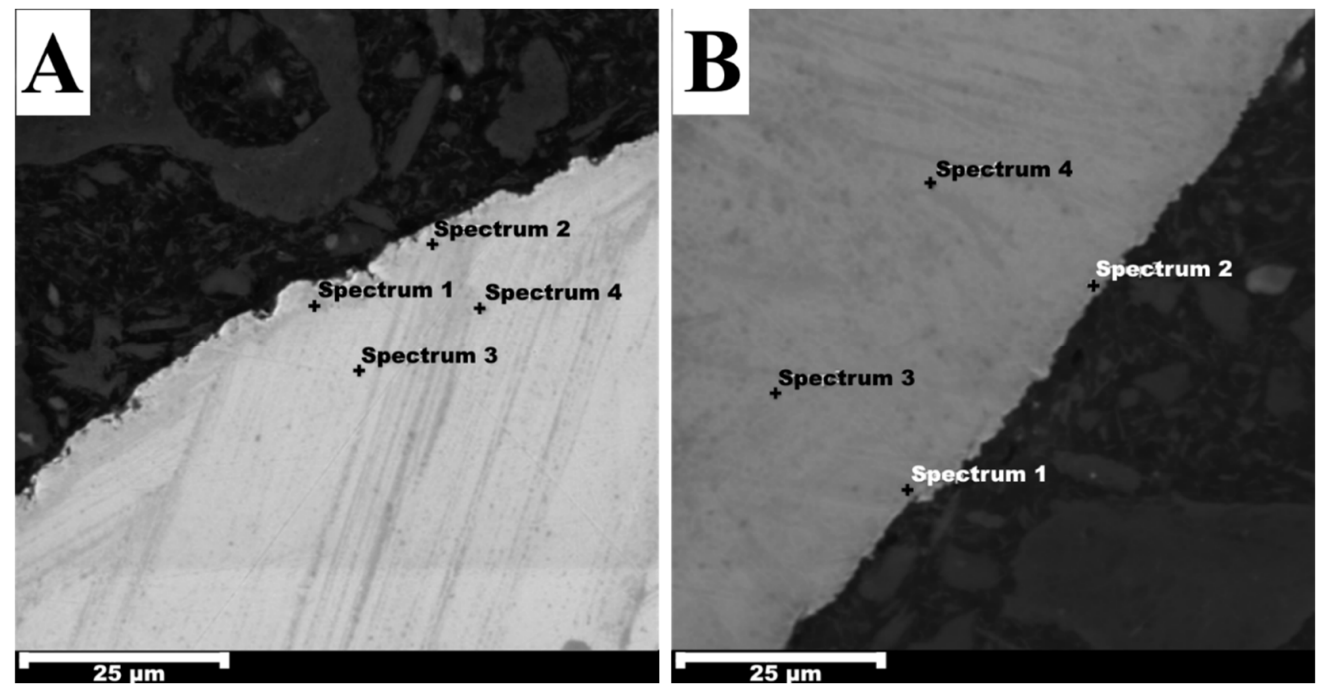

Figure 5. SEM images of cross-section of the sample after dealloying: (A) alloy after $3000 \mathrm{~s}$; (B) alloy after $6000 \mathrm{~s}$.

Table 2. EDS analysis of cross-section of the sample after dealloying.

\begin{tabular}{cccccc}
\hline Figure 5A & Component & Spectrum 1 & Spectrum 2 & Spectrum 3 & Spectrum 4 \\
\hline & W, wt.\% & 88.25 & 88.75 & 86.22 & 86.31 \\
& Re, wt.\% & 11.75 & 11.25 & 13.78 & 13.69 \\
\hline Figure 5B & Component & Spectrum 1 & Spectrum 2 & Spectrum 3 & Spectrum 4 \\
\hline & W, wt.\% & 90.66 & 90.73 & 88.63 & 88.36 \\
& Re, wt. $\%$ & 9.34 & 9.27 & 11.37 & 11.64 \\
\hline
\end{tabular}

The change in the concentration of rhenium from the volume to the front of the corrosion attack (dealloying) indicates that the process occurs not only on the surface of the sample but also in the pores formed at the initial moment of time.

A porous bimodal structure formed at the surface of tungsten during selective anodic dissolution of the tungsten (85 wt.\%)-rhenium (15 wt.\%) alloy in a solution of hydrochloric acid at $298 \mathrm{~K}$. The specific morphology of the resulting electrode materials based on mesoporous tungsten was studied.

\section{Discussion}

The criterion of thermodynamic probability of anodic processes in binary alloys is applicable for the process of dissolution of tungsten alloys with a more electronegative component (rhenium). The anode reaction involving a component with a more negative potential has the highest rate. For a tungsten-rhenium alloy, the process scheme is as follows:

$$
\begin{aligned}
& \mathrm{W}(\text { alloy } \mathrm{W}-\operatorname{Re})-\mathrm{ne}^{-}=\mathrm{W}^{\mathrm{n}+} \\
& \operatorname{Re}(\text { alloy } \mathrm{W}-\operatorname{Re})-\mathrm{ne}^{-}=\operatorname{Re}^{\mathrm{n}+}
\end{aligned}
$$

This process is accompanied by selective dissolution of rhenium from the surface layer of the alloy and the formation of a developed surface structure. The linear decrease in the 
thickness of the electrode and the difference in the partial diffusion coefficients of the alloy components were taken into account.

Selective anodic dissolution of one of the alloy components is quantitatively characterized by the coefficient of selective dissolution.

$$
\mathrm{z}_{\mathrm{A}}=\frac{\left(\mathrm{C}_{\mathrm{W}} / \mathrm{C}_{\mathrm{Re}}\right)_{\text {solution }}}{\left(\mathrm{C}_{\mathrm{W}} / \mathrm{C}_{\mathrm{Re}}\right)_{\text {alloy }}}
$$

A thermodynamic vacancy mechanism of this process has been developed for lowtemperature electrolytes [33]. Based on the Darken dependence of the logarithm of the mutual diffusion coefficient from the inverse temperature, the value of the self-diffusion coefficient at $298 \mathrm{~K}$ is estimated.

$$
\mathrm{D}=\mathrm{D}_{0} \cdot \exp \left(-\frac{\mathrm{E}}{\mathrm{RT}}\right)
$$

The external flow is caused by two effects: a change in the concentration gradient $\mathrm{C}_{\mathrm{Re}}$ and a decrease in the thickness of the electrode, causing the dissolution of the electronegative component.

The rate of dissolution of the alloy $\mathrm{q}_{\mathrm{Re}}^{0}\left(\mathrm{~mol} / \mathrm{cm}^{2} \mathrm{~s}\right)$ is given by the following equation:

$$
-q_{R e}^{0}=-D \frac{\partial C_{R e}}{\partial x}(0, t)-C_{A}(0, t) U_{L}(t)
$$

where $\mathrm{D}$ is the diffusion coefficient, $\mathrm{x}$ is the initial flat surface of the electrode, $\mathrm{t}$ is the time, and $U_{L}$ is the rate of linear loss of the alloy $(\mathrm{cm} / \mathrm{s})$.

$$
\mathrm{U}_{\mathrm{L}}=\mathrm{q}_{\operatorname{Re}} \mathrm{V}_{\text {alloy }}
$$

where $\mathrm{V}_{\text {alloy }}$ is the molar volume of the alloy.

The anodic dissolution of rhenium at the alloy-solution boundary, which is a powerful source of vacancies, where vacancies are absorbed by dislocations, and its diffusion from the depth of the alloy to the boundary cause the formation of vacancies in the alloy volume. There are two sources of vacancies with a total flow:

$$
\mathrm{J}_{\mathrm{V}}=\mathrm{J}_{\mathrm{V}}^{\prime} \uparrow \downarrow+\mathrm{J}_{\mathrm{V}}^{\prime \prime} \uparrow
$$

where $\mathrm{J}_{\mathrm{V}}^{\prime} \uparrow \downarrow$ is the flow of excess or lack of vacancies in comparison with the equilibrium concentration in the alloy volume, and $\mathrm{J}_{\mathrm{V}}^{\prime \prime} \uparrow$ is the flow of vacancies formed directly due to the process of selective dissolution of rhenium.

The change in the total volume of the formed voids (negative crystals) as a result of selective dissolution can be calculated:

$$
\Delta \mathrm{V}=\mathrm{C}^{-1} \int_{0}^{\mathrm{t}} \mathrm{J}_{\mathrm{V}}(\mathrm{t}) \mathrm{dt}
$$

The excess of vacancies at the boundary causes the linear loss of the alloy and the decrease in the thickness of the electrode. Vacancies can both move to the border and merge into the pores.

It is the supersaturation of vacancies in the alloy volume that causes them to merge into pores and form the so-called diffusion porosity or Frenkel effect. As the temperature increases, the alloy dissolves (decreasing in thickness) faster, the defectiveness decreases, and the boundary diffusion coefficient increases faster than the volume diffusion coefficient. With an increase in temperature, the relative contribution of diffusion along the boundaries decreases; at a lower temperature, the process of formation of sufficiently small pores prevails. 
The result of selective dissolution of the alloy is the formation of a surface layer with a modified composition. In the process of anodic dissolution, both the surface relief of the solid electrode and the proportion of the alloy components change and electrochemical destruction of the starting material occurs.

Studies of the regularity of selective dissolution are important for corrosiology and for the kinetics of electrochemical processes in general, as well as for electrochemical materials science and the production of structured materials for catalysis since it is necessary to take into account the real heterogeneity of solid metal surfaces.

To quantitatively characterize the type of destruction of intermetallic phases, the coefficient of selective dissolution $\mathrm{Z}_{\mathrm{A}}$ was used, which shows how many times the ratio of the amounts of tungsten to rhenium in the electrolyte solution was greater than the corresponding ratio in the alloy. With uniform dissolution, this coefficient is equal to unity, and with selective dissolution, it tends to infinity (tungsten transfers into the solution) or to zero (rhenium transfers into the solution) [33]. According to the obtained experimental data, the selectivity coefficient and the rate of linear loss of the alloy were calculated (Table 3).

Table 3. Compositions of solutions for electrochemical studies.

\begin{tabular}{cccc}
\hline Time, $\mathbf{s}$ & $\mathbf{3 0 0 0}$ & $\mathbf{6 0 0 0}$ & $\mathbf{3 0 , 0 0 0}$ \\
\hline $\mathrm{Z}_{\mathrm{A}}(\mathrm{W})$ & 1.08 & 1.29 & 2.35 \\
$\mathrm{Z}_{\mathrm{A}}(\mathrm{Re})$ & 0.92 & 0.77 & 0.41 \\
$\mathrm{U}_{\mathrm{L}}, \mathrm{sm} / \mathrm{s}$ & $1.4 \times 10^{-9}$ & $2.9 \times 10^{-9}$ & $7.2 \times 10^{-8}$ \\
\hline
\end{tabular}

Simultaneous occurrence of reactions (1) and (2) is thermodynamically possible at a value of applied anode potential exceeding the equilibrium potential of both alloy components. At an applied potential of $600 \mathrm{mV}$ (SCE), only the dissolution of rhenium is thermodynamically possible, which is consistent with the data of linear chronovoltammetry (Figure 1).

During the anodic dissolution of a tungsten alloy with a more electronegative component, such as rhenium, the alloy dissolves in the active state at a relatively low overvoltage of the anodic metal dissolution reaction. Under the conditions of anodic dissolution of a two-phase alloy, a structural-selective dissolution is most often observed.

\section{Conclusions}

The regularities of anodic dissolution of a two-component tungsten-rhenium alloy in an aqueous solution of hydrochloric acid were studied.

The parameters of the effective selective anodic dissolution of the tungsten-rhenium alloy, including the differences in applied potentials and electrolyte composition, were found. The existence of a bimodal structure on the tungsten surface after dealloying was proved.

The technological parameters such as the composition of the electrolyte, the process temperature, and the modes of anodic polarization, which provide the most efficient separation of tungsten and rhenium, were determined.

Author Contributions: Data curation, A.A.C.; Investigation, A.A.C.; Writing-review \& editing, E.V.N. All authors have read and agreed to the published version of the manuscript.

Funding: This research received no external funding.

Institutional Review Board Statement: Not applicable.

Informed Consent Statement: Not applicable.

Conflicts of Interest: The authors declare that they have no known competing financial interests or personal relationships that could have appeared to influence the work reported in this paper. 


\section{References}

1. Pu, Z.; Zhao, J.; Amiinu, I.S.; Li, W.; Wang, M.; He, D.; Mu, S. A universal synthesis strategy for P-rich noble metal diphosphidebased electrocatalysts for the hydrogen evolution reaction. Energy Environ. Sci. 2019, 12, 952-957. [CrossRef]

2. Ashraf, M.A.; Liu, Z.; Zhang, D. Novel 3-D urchin-like Ni-Co-W porous nanostructure as efficient bifunctional superhydrophilic electrocatalyst for both hydrogen and oxygen evolution reactions. Int. J. Hydrogen Energy 2020, 45, 17504-17516. [CrossRef]

3. Kotkondawar, A.V.; Mangrulkar, P.; Wanjari, S.; Maddigapu, P.R.; Rayalu, S. Photothermal hydrogen production from oxidative hydrolysis of electrochemically synthesized nano-sized zinc. Int. J. Hydrogen Energy 2019, 44, 6514-6524. [CrossRef]

4. Schmidt, O.; Gambhir, A.; Staffell, I.; Hawkes, A.; Nelson, J.; Few, S. Future cost and performance of water electrolysis: An expert elicitation study. Int. J. Hydrogen Energy 2017, 42, 30470-30492. [CrossRef]

5. Yang, Y.; Zhu, X.; Zhang, B.; Yang, H.; Liang, C. Electrocatalytic properties of porous Ni-Co-WC composite electrode toward hydrogen evolution reaction in acid medium. Int. J. Hydrogen Energy 2019, 44, 19771-19781. [CrossRef]

6. Xu, Y.; Xiao, X.; Ye, Z.; Zhao, S.; Shen, R.; He, C.; Zhang, J.; Li, Y.; Chen, X. Cage-Confinement Pyrolysis Route to Ultrasmall Tungsten Carbide Nanoparticles for Efficient Electrocatalytic Hydrogen Evolution. J. Am. Chem. Soc. 2017, 139, 5285-5288. [CrossRef] [PubMed]

7. Nady, H.; Negem, M. Ni-Cu nano-crystalline alloys for efficient electrochemical hydrogen production in acid water. RSC Adv. 2016, 6, 51111. [CrossRef]

8. Ngamlerdpokin, K.; Tantavichet, N. Electrodeposition of nickel-copper alloys to use as a cathode for hydrogen evolution in an alkaline media. Int. J. Hydrogen Energy 2014, 39, 2505-2515. [CrossRef]

9. Chang, Z.; Zhu, L.; Zhao, J.; Chen, P.; Chen, D.; Gao, H. NiMo/Cu-nanosheets/Ni-foam composite as a high performance electrocatalyst for hydrogen evolution over a wide $\mathrm{pH}$ range. Int. J. Hydrogen Energy 2020, 46, 3493-3503. [CrossRef]

10. Lotfi, N.; Shahrabi, T.; Yaghoubinezhad, Y.; Barati Darband, G.H. Electrodeposition of cedar leaf-like graphene Oxide@Ni-Cu@Ni foam electrode as a highly efficient and ultra-stable catalyst for hydrogen evolution reaction. Electrochim. Acta 2019, 326, 134949. [CrossRef]

11. Sun, Q.; Zhou, M.; Shen, Y.; Wang, L.; Ma, Y.; Li, Y.; Bo, X.; Wang, Z.; Zhao, C. Hierarchical nanoporous Ni(Cu) alloy anchored on amorphous $\mathrm{NiFeP}$ as efficient bifunctional electrocatalysts for hydrogen evolution and hydrazine oxidation. J. Catal. 2019, 373, 180-189. [CrossRef]

12. Nady, H.; Negem, M. Electroplated Zn-Ni nanocrystalline alloys as an efficient electrocatalyst cathode for the generation of hydrogen fuel in acid medium. Int. J. Hydrogen Energy 2018, 43, 4942-4950. [CrossRef]

13. Kuznetsov, V.V.; Gamburg, Y.D.; Zhulikov, V.V.; Batalov, R.S.; Filatova, E.A. Re-Ni cathodes obtained by electrodeposition as a promising electrode material for hydrogen evolution reaction in alkaline solutions. Electrochim. Acta 2019, 317, 358-366. [CrossRef]

14. Youn, J.; Jeong, S.; Kang, H.; Kovendhan, M.; Park, C.; Jeon, K. Effect of carbon coating on Cu electrodes for hydrogen production by water splitting. Int. J. Hydrogen Energy 2019, 44, 20641-20648. [CrossRef]

15. Martins, P.; Lopes, P.; Ticianelli, E.A.; Stamenkovic, V.R.; Markovic, N.M.; Strmcnik, D. Hydrogen evolution reaction on copper: Promoting water dissociation by tuning the surface oxophilicity. Electrochem. Commun. 2019, 100, 30-33. [CrossRef]

16. Zhang, X.; Guo, T.; Liu, T.; Lv, K.; Wu, Z.; Wang, D. Tungsten phosphide (WP) nanoparticles with tunable crystallinity, W vacancies, and electronic structures for hydrogen production. Electrochim. Acta 2019, 323, 134798. [CrossRef]

17. Wu, L.; Pu, Z.; Tu, Z.; Amiinu, I.S.; Liu, S.; Wang, P.; Mu, S. Integrated design and construction of WP/W nanorod array electrodes toward efficient hydrogen evolution reaction. Chem. Eng. J. 2017, 327, 705-712. [CrossRef]

18. Nikitina, E.V.; Karfidov, E.A. Corrosion of construction materials of separator in molten carbonates of alkali metal. Int. J. Hydrogen Energy 2021, 46, 16925-16931. [CrossRef]

19. Chernyshev, A.A.; Darintseva, A.B.; Ostanina, T.N.; Panashchenko, I.A.; Orlova, A.A.; Novikov, A.E.; Artamonov, A.S. Electrocrystallization of metals on a rotating drum-cathode. Int. J. Hydrogen Energy 2021, 46, 16848-16856. [CrossRef]

20. Abd El-Hafez, G.M.; Mahmoud, N.H.; Walcarius, A.; Fekry, A.M. Evaluation of the electrocatalytic properties of Tungsten electrode towards hydrogen evolution reaction in acidic solutions. Int. J. Hydrogen Energy 2019, 44, 16487-16496. [CrossRef]

21. Badawy, W.A.; Abd El-Hafez, G.M.; Nady, H. Electrochemical performance of tungsten electrode as cathode for hydrogen evolution in alkaline solutions. Int. J. Hydrogen Energy 2015, 40, 6276-6282. [CrossRef]

22. Chen, L.; Fan, J.L.; Gong, H.R. Atomistic simulation of mechanical properties of tungsten-hydrogen system and hydrogen diffusion in tungsten. Solid State Commun. 2020, 306, 113772. [CrossRef]

23. Zhang, J.; Li, C.M. Nanoporous metals: Fabrication strategies and advanced electrochemical applications in catalysis, sensing and energy systems. Chem. Soc. Rev. 2012, 41, 7016-7031. [CrossRef] [PubMed]

24. Tappan, B.C.; Steiner, S.A.; Luther, E.P. Nanoporous Metal Foams. Angew. Chem. Int. Ed. 2010, 49, 4544-4565. [CrossRef]

25. Walcarius, A. Mesoporous materials and electrochemistry. Chem. Soc. Rev. 2013, 42, 4098-4140. [CrossRef]

26. Zhang, Q.; Zhang, Z. On the electrochemical dealloying of Al-based alloys in a NaCl aqueous solution. Phys. Chem. Chem. Phys. 2010, 12, 1453-1472. [CrossRef]

27. Graf, M.; Roschning, B.; Weissmüller, J. Nanoporous Gold by Alloy Corrosion: Method-Structure-Property Relationships. J. Electrochem. Soc. 2017, 164, C194. [CrossRef]

28. Hakamada, M.; Mabuchi, M. Preparation of Nanoporous Palladium by Dealloying: Anodic Polarization Behaviors of Pd-M (M=Fe, Co, Ni) Alloys. Mater. Trans. 2009, 50, 431-435. [CrossRef] 
29. Nikitina, E.V.; Karfidov, E.A.; Kazakovtseva, N.A. Anodic selective dissolution of copper alloys in chloride and carbonate melts. J. Alloy Compd. 2020, 845, 156238. [CrossRef]

30. Ye, L.; Ouyang, Z.; Chen, Y.; Liu, S. Recovery of rhenium from tungsten-rhenium wire by alkali fusion in $\mathrm{KOH}^{-} \mathrm{K}_{2} \mathrm{CO}_{3}$ binary molten salt. Int. J. Refract. Met. Hard Mater. 2020, 87, 105148. [CrossRef]

31. Kuznetsova, O.G.; Levin, A.M.; Sevostyanov, M.A.; Bolshih, A.O. The improvement of rhenium recovery technology from W-Re alloys. J. Phys. Conf. Ser. 2018, 1134, 012032. [CrossRef]

32. Entezari-Zarandi, A.; Azizi, D.; Nikolaychuk, P.A.; Larachi, F.; Pasquier, L.C. Selective Recovery of Molybdenum over Rhenium from Molybdenite Flue Dust Leaching Solution Using PC88A Extractant. Metals 2020, 10, 1423. [CrossRef]

33. Andreev, Y.Y. Electrochemistry of Metals and Alloys; High Education and Science: Moskow, Russia, 2016; 320p. 